Western University

Scholarship@Western

$12-6-2021$

\title{
Metal Release from a Biomedical CoCrMo Alloy in Mixed Protein Solutions Under Static and Sliding Conditions: Effects of Protein Aggregation and Metal Precipitation
}

\author{
Zheng Wei \\ Western University \\ Valentine Romanovski \\ Luimar Filho \\ Cecilia Persson \\ Yolanda S. Hedberg \\ Western University, yhedberg@uwo.ca
}

Follow this and additional works at: https://ir.lib.uwo.ca/chempub

Part of the Chemistry Commons

Citation of this paper:

Wei, Z., Romanovski, V., Filho, L. et al. Metal Release from a Biomedical CoCrMo Alloy in Mixed Protein Solutions Under Static and Sliding Conditions: Effects of Protein Aggregation and Metal Precipitation. $J$ Bio Tribo Corros 8, 19 (2022). https://doi.org/10.1007/s40735-021-00617-1 
Metal release from a biomedical CoCrMo alloy in mixed protein solutions under static and sliding conditions - effects of protein aggregation and metal precipitation

Zheng Wei ${ }^{1,2}$, Valentin Romanovski ${ }^{1,4,5}$, Luimar Filho ${ }^{6}$, Cecilia Persson ${ }^{6}$, Yolanda Susanne Hedberg $1,2,3 *$

DOI: $10.1007 / \mathrm{s} 40735-021-00617-1$

${ }^{1}$ Division of Surface and Corrosion Science, Department of Chemistry, School of Engineering Sciences in Chemistry, Biotechnology and Health, KTH Royal Institute of Technology, SE-100 44, Stockholm, Sweden

${ }^{2}$ Dept. Chemistry, University of Western Ontario, 1151 Richmond Street, London, Ontario, N6A 5B7, Canada

${ }^{3}$ Surface Science Western, University of Western Ontario, 999 Collip Circle, London, Ontario, N6G 0J3, Canada

${ }^{4}$ Institute of General and Inorganic Chemistry, National Academy of Sciences of Belarus, 220072 Minsk, Belarus

${ }^{5}$ Science and Research Centre of Functional Nano-Ceramics, National University of Science and Technology "MISIS", 119049, Lenin av., 4, Moscow, Russia

${ }^{6}$ Uppsala University, Division of Applied Materials Science, Department of Materials Science, Box 534, 75121 Uppsala, Sweden

*corresponding author: email: yhedberg@uwo.ca; phone: (+1) (519) 661-2111 ext. 86248.

Running head: Metal release from CoCrMo in mixed protein solutions 


\begin{abstract}
Biomedical materials made of cobalt-chromium-molybdenum (CoCrMo) alloys are commonly used in artificial prostheses and dental implants, which are exposed to friction and load. The release of $\mathrm{Co}, \mathrm{Cr}$, and Mo from these surfaces is governed by physical and chemical processes. The extent of measured metal release from biomedical CoCrMo alloys into mixed protein solutions may be influenced by protein aggregation and metal precipitation effects. Metal release from, and the surface composition of, a CoCrMo alloy was investigated in physiological relevant solutions (phosphate buffered saline, PBS, with varying concentrations of fibrinogen from bovine plasma and/or bovine serum albumin) at $\mathrm{pH} 7.3$ in static and sliding conditions for time periods between 1 and 24 hours. Cr was strongly enriched in the surface oxide of CoCrMo in all solutions, which corresponded to metal release dominated by Co. PBS and the proteins could induce significant precipitation of metals and protein aggregates, which resulted in strongly underestimated released amounts of $\mathrm{Co}$ and $\mathrm{Cr}$, but not $\mathrm{Mo}$, especially under sliding conditions. Protein aggregates were found to precipitate on the surface of CoCrMo under static conditions. The friction coefficient was greater in PBS containing physiologically relevant concentrations of fibrinogen as compared to PBS alone.
\end{abstract}

Keywords: Metal release, protein aggregation, wear, Vroman effect, metal speciation

\title{
Declarations
}

Funding: The Swedish Research Council (VR, grant no. 2015-04177), the Taiho Kogyo Tribology Research Foundation (grant no. 20B04), the European Union (grant number FP7-NMP-2012-310477 (Life Long Joints project)), EBW+ Project Erasmus Mundus Programme, Action 2 - STRAND 1, Lot 9 (Latin America), Brazil (Grant number 2014-0982), Wolfe-Western fellowship, Canada [grant number: 2020]; Canada Research Chairs Program [grant number: 950 - 233099], Natural Sciences and Engineering Research Council of Canada [RGPIN-2021-03997].

Conflicts of interest/Competing interests: The authors declare no conflicts of interest.

Availability of data and material: Raw data are available from the corresponding author upon reasonable request. 
Code availability (software application or custom code): not applicable.

Authors' contributions: ZW conducted most measurements and drafted the manuscript. VR assisted in the measurements (digestion and AAS). LF assisted in the pin-on-disk measurements. $\mathrm{CP}$ supervised the pin-on-disk measurements. YH supervised the study. All authors read and approved the final version of the manuscript.

\section{Acknowledgement}

Prof. Inger Odnevall, at Div. Surface and Corrosion Science, KTH Royal Institute of Technology, and Dr. Jonas Hedberg, Surface Science Western, Western University, and earlier KTH, are highly acknowledged for valuable discussions and assistance in supervision and experiments. 


\section{INTRODUCTION}

Biomedical materials made of cobalt-chromium (28 wt\%)-molybdenum (6 wt $\%)$ (CoCrMo) alloys are commonly used in artificial prostheses and dental implants for surfaces that are exposed to friction and load [1,2]. CoCrMo alloys possess both a high corrosion resistance and excellent wear resistance [2] making them relatively highresistant to tribocorrosion processes, which involve both mechanical, electrochemical, and in some cases other chemical processes, often in a synergistic way [2-5].

The release of $\mathrm{Co}^{\mathrm{II}}$ and $\mathrm{Cr}^{\mathrm{III}}$ ions and complexes, or wear nanoparticles, from CoCrMo surfaces into protein-rich physiological environments can result in protein binding [69], protein aggregation [10, 11], and adverse health effects [12] such as allergic reactions [13] and neurodegenerative diseases [14-16].

The interface between CoCrMo and softer materials such as ultra-high molecularweight polyethylene (UHMWPE), the common interface in so-called metal-on-polymer (MOP) hip joint prostheses, is challenging to understand in the presence of proteins, as these can induce lubricating effects [17, 18], aggregate due to metal release [10], and induce dominating chemical release mechanisms that are difficult to investigate $[4,19]$.

A physiological environment consists not only of one type of protein. The presence of several types of proteins can influence the adsorption, surface protein exchange rate, and hence lubricating properties and chemically induced release mechanisms. The Vroman effect describes the substitution of surface-adsorbed proteins by proteins with a higher surface affinity, which are often larger in size [20]. This exchange can be very rapid (seconds to minutes) [21]. The metal released from stainless steels of grades AISI 316L and 303 was found to be influenced by the Vroman effect [22]. A corresponding study on CoCrMo alloy has not been published yet.

Under shear conditions, protein aggregates can also be formed mechanically [23, 24]. Further, it has been shown that released molybdate ions from CoCrMo alloys can change the structure of the adsorbed protein film by cross-linking proteins, forming a gel-like structure $[25,26]$.

This study aimed at investigating the effect of different proteins (albumin and fibrinogen) on metal release from CoCrMo in static and sliding conditions.

\section{MATERIALS AND METHODS}

\subsection{Materials}

Specimens used in metal release studies were biomedical grade cobalt-chromium (28 $\mathrm{wt} \%)$-molybdenum (6 wt\%) (CoCrMo) alloy disks of $22 \mathrm{~mm}$ in diameter and $2 \mathrm{~mm}$ in thickness (a total surface are of $9.0 \mathrm{~cm}^{2}$ ), supplied by Ionbond, Switzerland, and certified by Aubert \& Duval, France. They were produced by means of vacuum 
induction melting followed by electroslag remelting and warm working. The materials conformed to ASTM F1537 Alloy 1. For specimens used in the wear test, the CoCrMo disks were $21.9 \mathrm{~mm}$ in diameter and $5 \mathrm{~mm}$ in thickness (ASTM F1537-11), supplied by the same supplier and of similar manufacturing and composition.

\subsection{Metal release investigations in static conditions (without friction)}

Prior to metal release tests, all disks were grinded by 1200 grit $\mathrm{SiC}$ paper with water, and ultrasonically cleaned in acetone and isopropyl alcohol for $7 \mathrm{~min}$, subsequently. After that, the cleaned disks were dried with nitrogen gas at room temperature and stored in a desiccator at room temperature for 24 hours to form a well-defined passive film on the surface prior to exposure. During exposure, the ratio of the specimen surface area to solution volume was approximately $1 \mathrm{~cm}^{2} / \mathrm{mL}\left(0.9 \mathrm{~cm}^{2}\right.$ surface area in $9 \mathrm{~mL}$ solution) and exactly measured for each specimen. Exposure was conducted in closed and acid-cleaned polyethylene vessels and the specimens were completely immersed in the solution. For all tested conditions (solutions and time points), one blank sample without any specimen and triplicate samples (with individual specimens exposed in similar conditions) were exposed. Phosphate buffered saline (PBS), adjusted with 50\% ultrapure $\mathrm{NaOH}$ to $\mathrm{pH} 7.3 \pm 0.1$, containing $8.77 \mathrm{~g} / \mathrm{L} \mathrm{NaCl}, 1.28 \mathrm{~g} / \mathrm{L} \mathrm{Na}_{2} \mathrm{HPO}_{4}$, and 1.36 $\mathrm{g} / \mathrm{L} \mathrm{KH}_{2} \mathrm{PO}_{4}$ (all analytical grade), PBS with 2.67 or $10 \mathrm{~g} / \mathrm{L}$ fibrinogen from bovine plasma (Fbn, Sigma Aldrich F8630, Sweden) and/or $40 \mathrm{~g} / \mathrm{L}$ bovine serum albumin (BSA, Sigma Aldrich A7906, Sweden) were prepared in ultrapure water (resistivity of $18.2 \mathrm{M} \Omega \mathrm{cm}$, Millipore, Sweden). All exposures were conducted in a Stuart platformrocker incubator at $37 \pm 0.5{ }^{\circ} \mathrm{C}$ in dark conditions and agitated bi-linearly at $12^{\circ}$ inclination and 22 cycles/min. Independent CoCrMo disks were exposed in five different single solutions for 4 and $24 \mathrm{~h}$, compiled in Table 1. Sequential tests, in which half of the solution was exchanged after $5 \mathrm{~h}$, are further schematically illustrated in Fig. 1. The two subsequent solutions are specified in Table 2 and the solution sampling was conducted after 1, 4, 6, and $24 \mathrm{~h}$ for each exposure vessel. After exposure, CoCrMo disks were separated from solutions, rinsed by ultrapure water, and dried by nitrogen gas. They were then stored in a desiccator $(<10 \%$ relative humidity) before examination by means of light optical microscopy (LOM), scanning electron microscopy (SEM), energy dispersive X-ray spectroscopy (EDS) and X-ray photoelectron spectroscopy (XPS).

Table 1. Single solution exposures and durations (without friction).

\begin{tabular}{ll}
\hline Media & Duration \\
\hline PBS, pH 7.2-7.4 & $4 \mathrm{~h}, 24 \mathrm{~h}$ \\
PBS+Fbn (10g/L), pH 7.2-7.4 & $4 \mathrm{~h}, 24 \mathrm{~h}$ \\
PBS+BSA (10g/L), pH 7.2-7.4 & $4 \mathrm{~h}, 24 \mathrm{~h}$ \\
PBS+Fbn (10g/L)+BSA (10g/L), pH 7.2-7.4 & $4 \mathrm{~h}, 24 \mathrm{~h}$ \\
PBS+Fbn (2.67g/L)+BSA (40g/L), $\mathrm{pH} 7.2-7.4$ & $4 \mathrm{~h}, 24 \mathrm{~h}$ \\
\hline
\end{tabular}


The solution samples were acidified to a $\mathrm{pH}<2$ with $65 \%$ ultrapure $\mathrm{HNO}_{3}$ and stored frozen at $-25{ }^{\circ} \mathrm{C}$. All vessels were acid-cleaned in $10 \% \mathrm{HNO}_{3}$ for at least $24 \mathrm{~h}$, washed 4 times by ultrapure water, and dried in ambient conditions.

Table 2. Sequential solution exposures (all sampled after 1, 4, 6, $24 \mathrm{~h}$ ). The volumes shown are for tests without friction (static conditions). They were $45 \mathrm{~mL}$ (first solution) and $20 \mathrm{~mL}$ (second solution) in the case of the tests with friction (sliding conditions).

\begin{tabular}{ll}
\hline First solution $(10 \mathrm{~mL})$ & Second solution $(5 \mathrm{~mL})$ \\
\hline PBS, pH 7.2-7.4 & PBS, pH 7.2-7.4 \\
PBS+BSA (40 g/L), pH 7.2-7.4 & PBS+BSA (40 g/L), $\mathrm{pH} 7.2-7.4$ \\
PBS+Fibrinogen (2.67 g/L), pH 7.2-7.4 & PBS+Fibrinogen $(2.67 \mathrm{~g} / \mathrm{L}), \mathrm{pH} 7.2-7.4$ \\
PBS+BSA (40 g/L), pH 7.2-7.4 & PBS+Fibrinogen $(5.34 \mathrm{~g} / \mathrm{L}), \mathrm{pH} 7.2-7.4$ \\
\hline
\end{tabular}

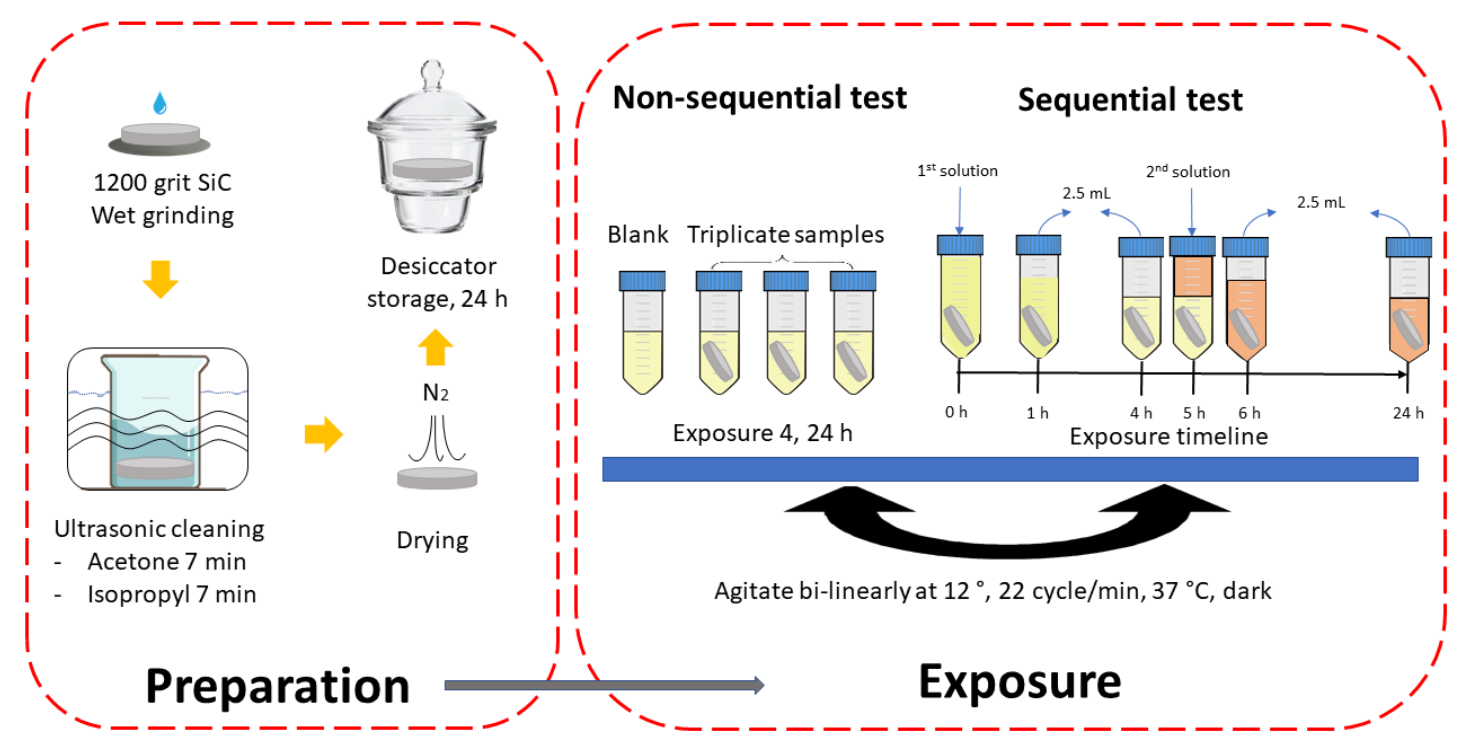

Figure 1. Illustration of the non-sequential test procedure, and the sequential test procedure, for metal release testing in static conditions (without friction). Conditions: $37^{\circ} \mathrm{C}$, bilinear agitation ( 22 cycles/minute, $\left.12^{\circ}\right)$, darkness.

\subsection{Metal release investigations under sliding conditions}

Tests of CoCrMo disks under friction (sliding conditions) were performed in the form of a multidirectional test against a flat ultra-high molecular weight polyethylene 
(UHMWPE) pin (GUR $\left.{ }^{\circledR} 1020\right)$ of $1.905 \mathrm{~cm}$ length and $0.9525 \pm 0.005 \mathrm{~cm}$ diameter, illustrated in Fig. 2. The applied load was set to $150 \mathrm{~N}$, the frequency to $2 \mathrm{~Hz}$ and the stroke length to $7 \mathrm{~mm}$ on each sample. The contact pressure was $2.1 \mathrm{MPa}$, which is comparable to the $9 \mathrm{MPa}$ in a CoCrMo-UHMWPE hip joint [27] and 150-fold higher than the contact pressure, for which an increase in friction coefficient was detected in the presence of metal-induced protein aggregates [28]. The test was run for 172,800 cycles $(24 \mathrm{~h})$. The CoCrMo disks were exposed to the sequential solutions specified in Table 2, with a total volume of $45 \mathrm{~mL}$ (first solution) and $20 \mathrm{~mL}$ (second solution). The specimens were completely immersed throughout the test. Four parallel measurements were conducted on a blank sample (without CoCrMo disk) and triplicate samples in a heated stainless steel holder and plastic container (PMMA) at $37 \pm 3{ }^{\circ} \mathrm{C}$. This procedure was conducted four times for all four sequential solution in the same order as in Table 2 (starting with PBS). Prior to the first measurement and in between each measurement, the sample holders were cleaned with a liquid ultrasonic cleaning detergent for 10 minutes in an ultrasonic bath, then rinsed in deionized water three times for 3 minutes in an ultrasonic bath, then soaked in $95 \%$ methyl alcohol for 5 minutes and finally dried with nitrogen gas. The friction coefficient was monitored throughout the exposure, and solution samples were taken after 1, 4, 6, and $24 \mathrm{~h}(10 \mathrm{~mL})$. The solution samples were further centrifuged using an Eppendorf centrifuge 5702 (3,000 relative centrifugal force for $10 \mathrm{~min})$ and separated into supernatant $(5 \mathrm{~mL}$, denoted "top" in the following) and the remaining solution ( $5 \mathrm{~mL}$, denoted "bottom" in the following). All solution samples were acidified to a $\mathrm{pH}<2$ with $65 \%$ ultrapure $\mathrm{HNO}_{3}$ and stored frozen at $-25^{\circ} \mathrm{C}$.

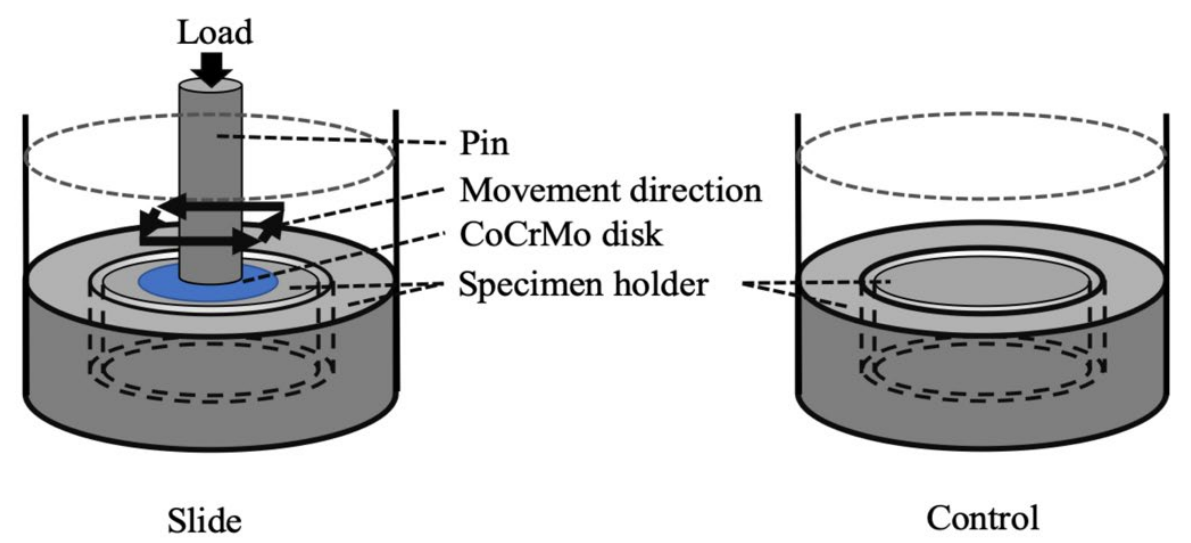

Figure 2. Schematic illustration of the pin movement on the CoCrMo disk set-up for testing under sliding conditions. 


\subsection{Digestion}

Prior to trace metal analysis, the solution samples were digested to avoid the formation of hydrogels in the protein-rich solution samples and a potential loss of analyte. After unfreezing, $2 \mathrm{~mL}$ of single solution samples (Table 1) or $2.5 \mathrm{~mL}$ of sequential solution samples (Table 2) and the top or bottom solution samples of the tests in sliding conditions were diluted with ultrapure water and at least $0.5 \mathrm{~mL} 30 \%$ ultrapure hydrogen peroxide to a total volume of approximately $10 \mathrm{~mL}$. The samples were then digested using an UV digester (Metrohm 705 UV digester) at a temperature between 90 and $95{ }^{\circ} \mathrm{C}$ for several hours until the solutions were transparent and odorless. The final volume was recorded, and the dilution factor (DF) for each solution sample was calculated based on the recorded volume divided by the initial volume of the added sample solution. The measured concentration of each solution sample was then multiplied by the individual sample DF and further treated as described in the next section.

\subsection{Atomic absorption spectroscopy $(A A S)$}

The amounts of $\mathrm{Co}, \mathrm{Cr}$ and $\mathrm{Mo}$ in the solution samples were analyzed by means of graphite furnace atomic absorption spectroscopy, GF-AAS (Perkin Elmer AA800 analyst). Quality control samples of known concentrations were analyzed every fifth sample (after four regular solution samples). The calibration was based on one blank sample $\left(1 \%\right.$ ultrapure $\left.\mathrm{HNO}_{3}\right)$ and at least three $\mathrm{Co}, \mathrm{Cr}$, or Mo containing standards covering the sample concentration range. If the sample concentrations were higher than the calibration range, the samples were diluted and reanalyzed. Triplicate readings were performed for each solution sample. The limits of detection (based on three times the highest standard deviation of the blank values) were $1.7 \mu \mathrm{g} / \mathrm{L} \mathrm{Co}, 1.2 \mu \mathrm{g} / \mathrm{L} \mathrm{Cr}$, and 0.9 $\mu \mathrm{g} / \mathrm{L}$ Mo. The blank values were negligible (close to or below limits of detection) in the case of the tests in static conditions.

For metal release estimations from the tests in static conditions, the released metal amount per exposed specimen surface area $\left(\mu \mathrm{g} / \mathrm{cm}^{2}\right)$ was determined by averaging the concentrations of the triplicate samples, subtracting the blank sample concentrations from that, multiplying the value with the solution volume, and dividing the value by the specimen surface area. The solution volume was $10 \mathrm{~mL}$ for the single solution measurements (Table 1), and $10 \mathrm{~mL}$ for $1 \mathrm{~h}, 7.5 \mathrm{~mL}$ for $4 \mathrm{~h}, 10 \mathrm{~mL}$ for $6 \mathrm{~h}$, and $7.5 \mathrm{~mL}$ for $24 \mathrm{~h}$ time points in the sequential tests (Table 2).

For the tests in sliding conditions, a significant amount of Co, Cr, and Mo was detected in the blank sample solutions due to the stainless steel holders in the test-setup, further described and discussed in the result and discussion sections. Therefore, these solutions were treated as samples and are denoted control in the following. The released amount of $\mathrm{Co}, \mathrm{Cr}$ and $\mathrm{Mo}$ was calculated by multiplying the concentration value with the solution volume, and dividing the value by the surface area. The surface area was 
estimated to $50.98 \mathrm{~cm}^{2}$ for the control samples (based on the stainless steel sample holder surface area in contact with the solution) and equally to $50.98 \mathrm{~cm}^{2}$ for the CoCrMo disk specimens in the wear test (considering the contribution from the sample holder). The solution volume in the wear tests was $45 \mathrm{~mL}, 35 \mathrm{~mL}, 45 \mathrm{~mL}$, and $35 \mathrm{~mL}$, for $1,4,6$, and $24 \mathrm{~h}$ time points, respectively.

\subsection{X-ray photoelectron spectroscopy (XPS)}

X-ray photoelectron spectroscopy (XPS, Ultra DLD spectrometer, Kratos Analytical, Manchester, UK) was used to analyze the surface composition of the CoCrMo disks after exposure in static conditions (selected specimens). All measurements were performed on two separate surface areas of each disk, sized approximately $300 \times 700$ $\mu \mathrm{m}$ by using a monochromatic $\mathrm{Al} \mathrm{K \alpha} \mathrm{X}$-ray source (150W). The information depth was equal to, or less than, $10 \mathrm{~nm}$. The measurements were based on the CoCrMo disks, which were exposed in static conditions to the four sequential solutions (Table 2) and on one non-exposed (only grinded, cleaned, and air-exposed) CoCrMo disk for reference. The pass energy used for detailed spectra was $20 \mathrm{eV}$, generated for Co $2 \mathrm{p}, \mathrm{Cr}$ $2 \mathrm{p}, \mathrm{O} 1 \mathrm{~s}, \mathrm{~N} 1 \mathrm{~s}, \mathrm{C} 1 \mathrm{~s}$ and Mo $3 \mathrm{~d}$. The $\mathrm{C} 1 \mathrm{~s}$ binding energy at $285.0 \mathrm{eV}$ was used as binding energy reference.

\subsection{Statistical calculations}

In order to identify the statistical significance of any differences among conditions, a student's t-test of unpaired data with unequal variance was used in the software KaleidaGraph 4.0 for independent samples. The student's t-test of paired data was used for dependent samples (same CoCrMo disk but different time points). A p-value below 0.05 was considered as a statistically significant difference.

\section{RESULTS AND DISCUSSION}

\subsection{Non-sequential release of metals in static conditions}

The total amount of $\mathrm{Co}, \mathrm{Cr}$ and Mo in solution samples after contact with the CoCrMo disks for $4 \mathrm{~h}$ and $24 \mathrm{~h}$ in PBS, PBS $+10 \mathrm{~g} / \mathrm{L} \mathrm{Fbn}, \mathrm{PBS}+10 \mathrm{~g} / \mathrm{L}$ BSA, PBS $+10 \mathrm{~g} / \mathrm{L}$ $\mathrm{BSA}+10 \mathrm{~g} / \mathrm{L}$ Fbn and PBS $+40 \mathrm{~g} / \mathrm{L} \mathrm{BSA}+2.67 \mathrm{~g} / \mathrm{L}$ Fbn are presented in Fig. 3. The released and non-precipitated amounts of $\mathrm{Co}, \mathrm{Cr}$ and Mo increased in all cases with time, except for PBS $+40 \mathrm{~g} / \mathrm{L} \mathrm{BSA}+2.67 \mathrm{~g} / \mathrm{L}$ Fbn (not significant $\mathrm{p}=0.37$ ). Although the reduction in concentration of Co between the $4 \mathrm{~h}$ and $24 \mathrm{~h}$ in the solution PBS $+40 \mathrm{~g} / \mathrm{L}$ $\mathrm{BSA}+2.67 \mathrm{~g} / \mathrm{L}$ Fbn was not statistically significant, there was a descending tendency. This may be caused by metal-protein complexation and concomitant agglomeration [6, 29], which can result in precipitation of metals from solution. Compared with PBS, there was no statistically significant change for the released amounts of Co in the presence of albumin or fibrinogen after 4 and $24 \mathrm{~h}$. According to previous results [30, 31], BSA would accelerate the corrosion of CoCrMo alloy in PBS solution. However, there was no detected increase in metal release in static conditions in this study. On the 
contrary, there was a significant decrease of released amount of Mo in the presence of albumin after $4 \mathrm{~h}$. This phenomenon may be caused by precipitation of metals from solution. Clark and Williams [32] investigated the effects of proteins on metal corrosion.

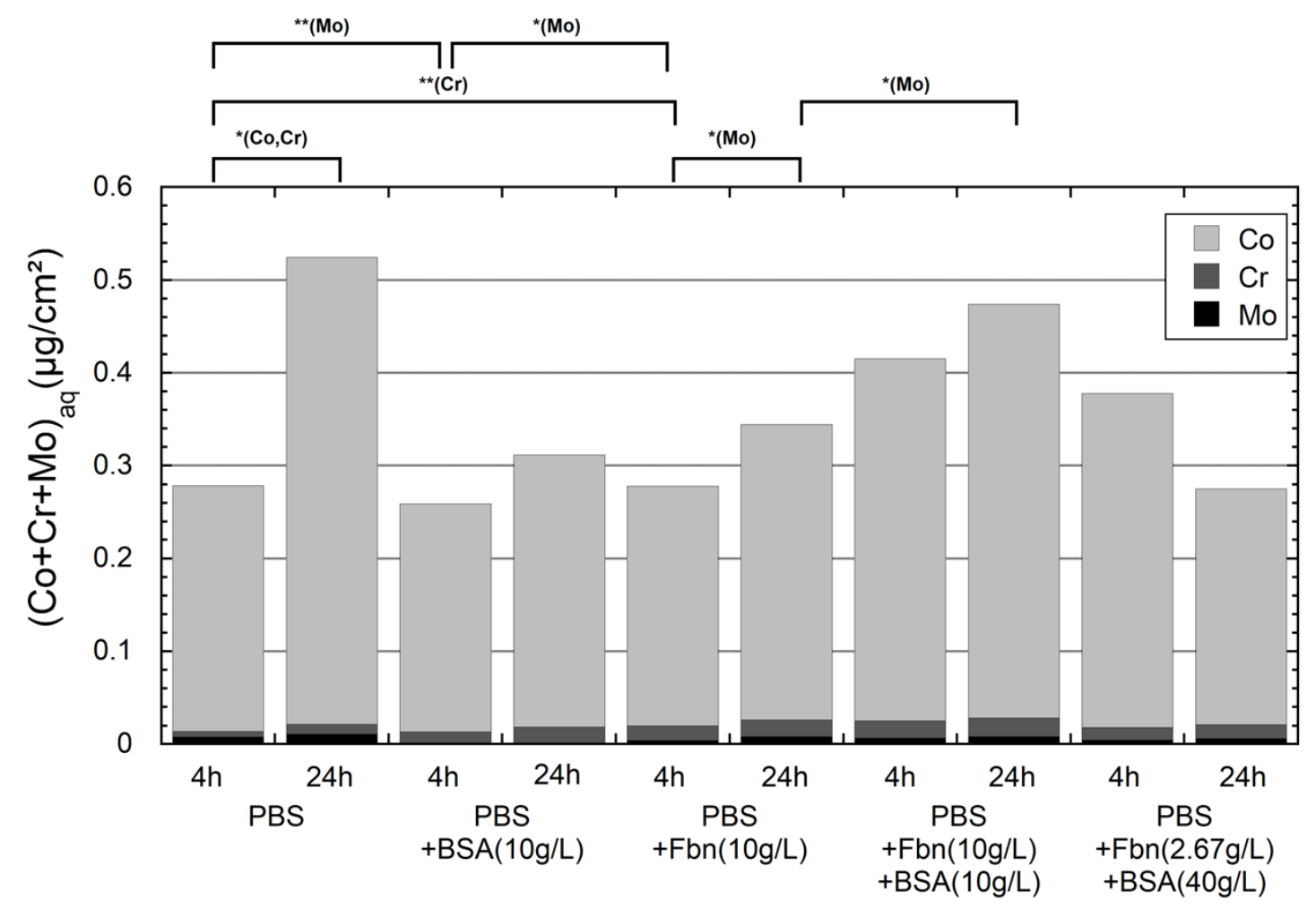

Figure 3. Released and non-precipitated amounts $\left(\mu \mathrm{g} / \mathrm{cm}^{2}\right)$ of $\mathrm{Co}, \mathrm{Cr}$ and $\mathrm{Mo}$ in solution from CoCrMo disks exposed to PBS, PBS+BSA (10g/L), PBS+Fbn (10g/L), PBS+Fbn $(10 \mathrm{~g} / \mathrm{L})+\mathrm{BSA}(10 \mathrm{~g} / \mathrm{L})$ or PBS+Fbn $(2.67 \mathrm{~g} / \mathrm{L})+\mathrm{BSA}(40 \mathrm{~g} / \mathrm{L})$ at $\mathrm{pH} 7.2-7.4$ after $4 \mathrm{~h}$ and $24 \mathrm{~h}$ at $37^{\circ} \mathrm{C}$. Significant differences are indicated by asterisks: $* \mathrm{p}<0.05,{ }^{*} \mathrm{p}<0.01$; $\mathrm{n}=3$.

They showed that both BSA and Fbn could accelerate the dissolution of Co and $\mathrm{Cr}$ from pure cobalt and chromium metal powders compared with saline alone, while the opposite (inhibited dissolution) was the case for Mo powder, which dissolved at a significantly higher rate than the $\mathrm{Co}$ and $\mathrm{Cr}$ powder. As discussed further below, this different influence of proteins on $\mathrm{Co}, \mathrm{Cr}$, and Mo release (and precipitation) might be explained by the fact that $\mathrm{Cr}$ and $\mathrm{Co}$ are binding to proteins, while $\mathrm{Mo}$ (which is released as negatively charged molybdate ion) is most probably not binding to proteins. In static conditions, the measured amounts of metals in solution were relatively similar in all these different solutions. These findings are different compared with findings for the sequential solutions (next section), but similar to previous findings in similar exposure conditions [33]. 


\subsection{Sequential release of metals in static conditions}

The released and non-precipitated amounts of $\mathrm{Co}, \mathrm{Cr}$ and $\mathrm{Mo}$ in four sequential solutions are shown in Fig. 4. The released amount of Co (Fig. 4a), Cr (Fig. 4b) and Mo (Fig. 4c) in the first sequential solution, which was PBS followed by PBS ("PBS, PBS"), was slightly higher than the other three protein-containing solutions.
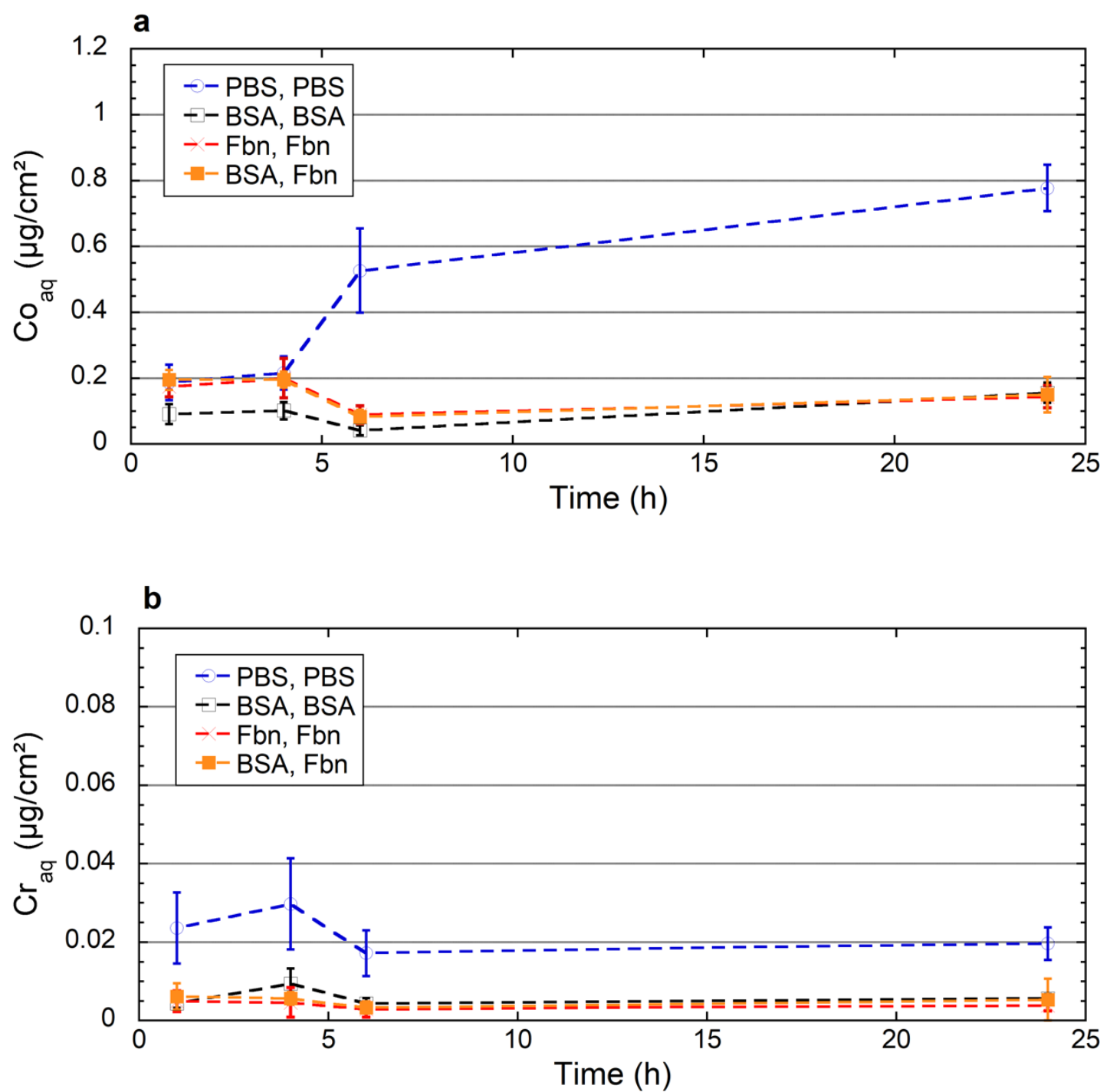


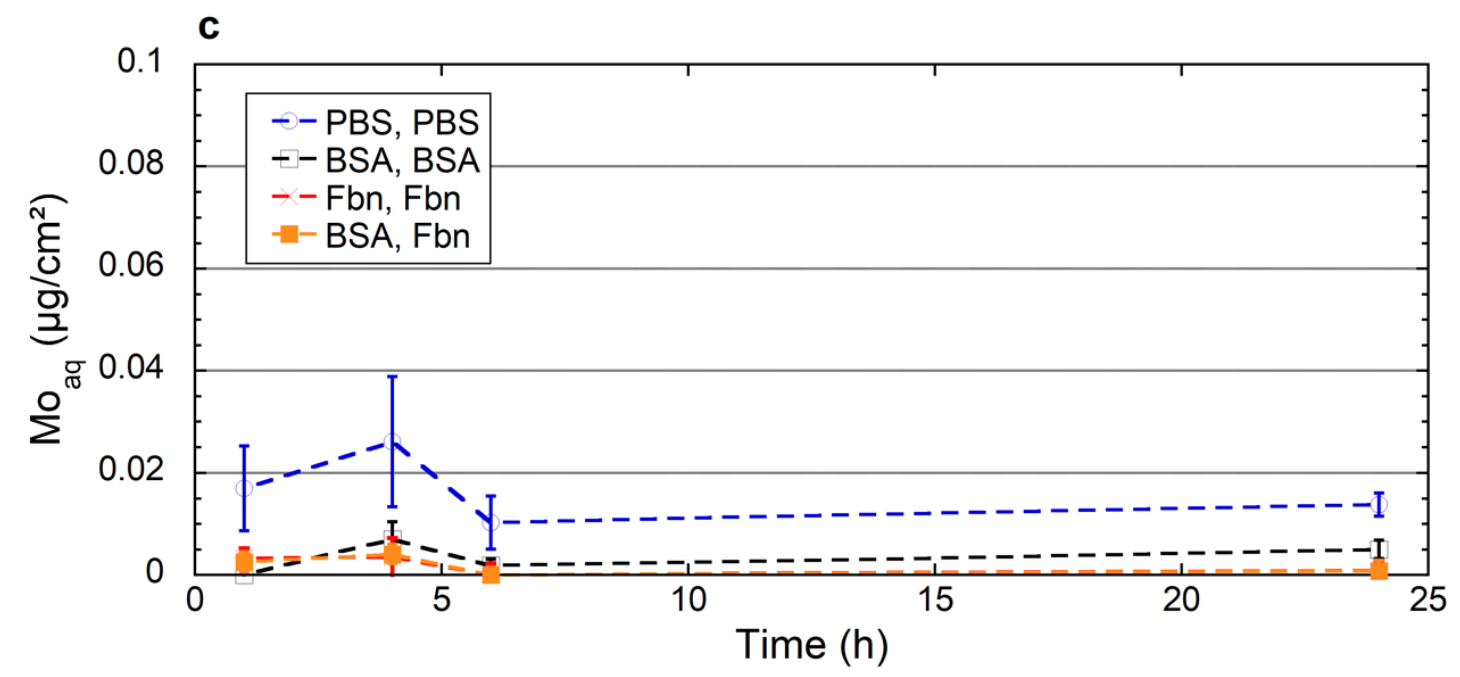

Figure 4. Released and non-precipitated amounts of Co (a), Cr (b) and Mo (c) in solution from disks of a CoCrMo alloy exposed to four sequential solutions ( $\mathrm{pH}$ 7.27.4); PBS followed by PBS (PBS, PBS), PBS $+40 \mathrm{~g} / \mathrm{L}$ BSA followed by PBS $+40 \mathrm{~g} / \mathrm{L}$ BSA (BSA, BSA), PBS+2.67 g/L Fbn followed by PBS+2.67 g/L Fbn (Fbn, Fbn), and PBS $+40 \mathrm{~g} / \mathrm{L} \mathrm{BSA}$ followed by $2.67 \mathrm{~g} / \mathrm{L} \mathrm{Fbn}\left(\mathrm{BSA}, \mathrm{Fbn}\right.$ ); exposed at $37{ }^{\circ} \mathrm{C}$ and sampled after 1, 4, 6 and $24 \mathrm{~h}$. The second solution was added after $5 \mathrm{~h}$. The error bars show the standard deviation of independent triplicate disks.

The released amount of $\mathrm{Co}, \mathrm{Cr}$ and Mo was almost similar in the three proteincontaining sequential solutions ("BSA, BSA", "Fbn, Fbn" and "BSA, Fbn"). The concentration of Co in solution increased with time only in the "PBS, PBS" sequence, but not for the protein-containing solutions, Fig. 4a. This phenomenon could either indicate that there is a protective (hindering) effect of the proteins or that released metals are preferentially bound to proteins that precipitate from solution or cover the surface of the CoCrMo disk. This effect is also most probably influenced by the experimental set-up (Fig. 1), since all solution samples were pipetted from the top of the tubes, as in a previous study on stainless steel [22]. Protein aggregates were obviously visible on the CoCrMo surfaces, which have been immersed in the Fbncontaining solutions, Fig. 5. 

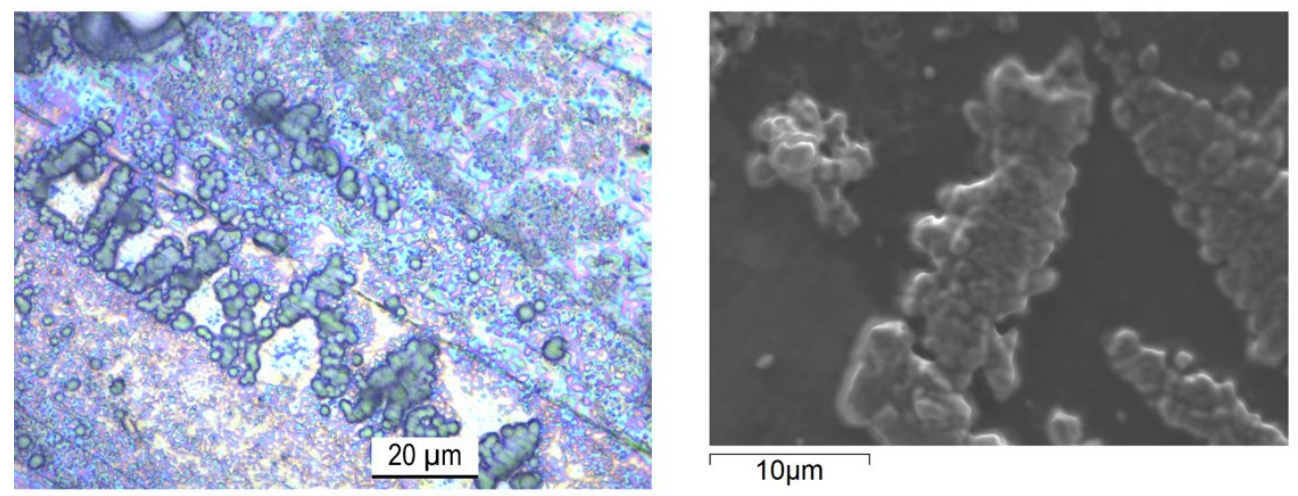

Figure 5. Representative LOM (left) and SEM (right) micrographs of a CoCrMo disk, which was exposed to PBS with Fbn $(10 \mathrm{~g} / \mathrm{L})$ for $24 \mathrm{~h}$ in static conditions.

The composition of these aggregates was confirmed as protein-originating (nitrogen, carbon, oxygen, and solution components, no main alloying elements) by energy dispersive X-ray spectroscopy, Table 3.

Table 3. EDS results of CoCrMo disks exposed to PBS with $10 \mathrm{~g} / \mathrm{L}$ Fbn for $24 \mathrm{~h}$, with a spot focus on the protein aggregates.

\begin{tabular}{lllllll}
\hline & $\mathrm{C}(\mathrm{wt} \%)$ & $\mathrm{N}(\mathrm{wt} \%)$ & $\mathrm{O}(\mathrm{wt} \%)$ & $\mathrm{Na}(\mathrm{wt} \%)$ & $\mathrm{P}(\mathrm{wt} \%)$ & $\mathrm{Cl}(\mathrm{wt} \%)$ \\
\hline $\mathrm{CoCrMo}$ & 32 & 6.2 & 5.6 & 27 & 1.5 & 29 \\
\hline
\end{tabular}

\subsection{Surface characterization after sequential exposures in static conditions}

The investigated outermost surface of CoCrMo revealed oxidized (deriving from oxides, hydroxides or oxyhydroxides) metal peaks in addition to common peaks deriving from adventitious carbon (contamination from the air). The relative metal composition (based on the mass of oxidized metals) of the outermost $(\leq 10 \mathrm{~nm})$ surface (hydr)oxide of CoCrMo disks after grinding (1200 grit $\mathrm{SiC}$ paper) and after exposure to the four sequential solutions for $24 \mathrm{~h}$ in static conditions is shown in Fig. 6, with binding energies and assignments shown in Table 4. 


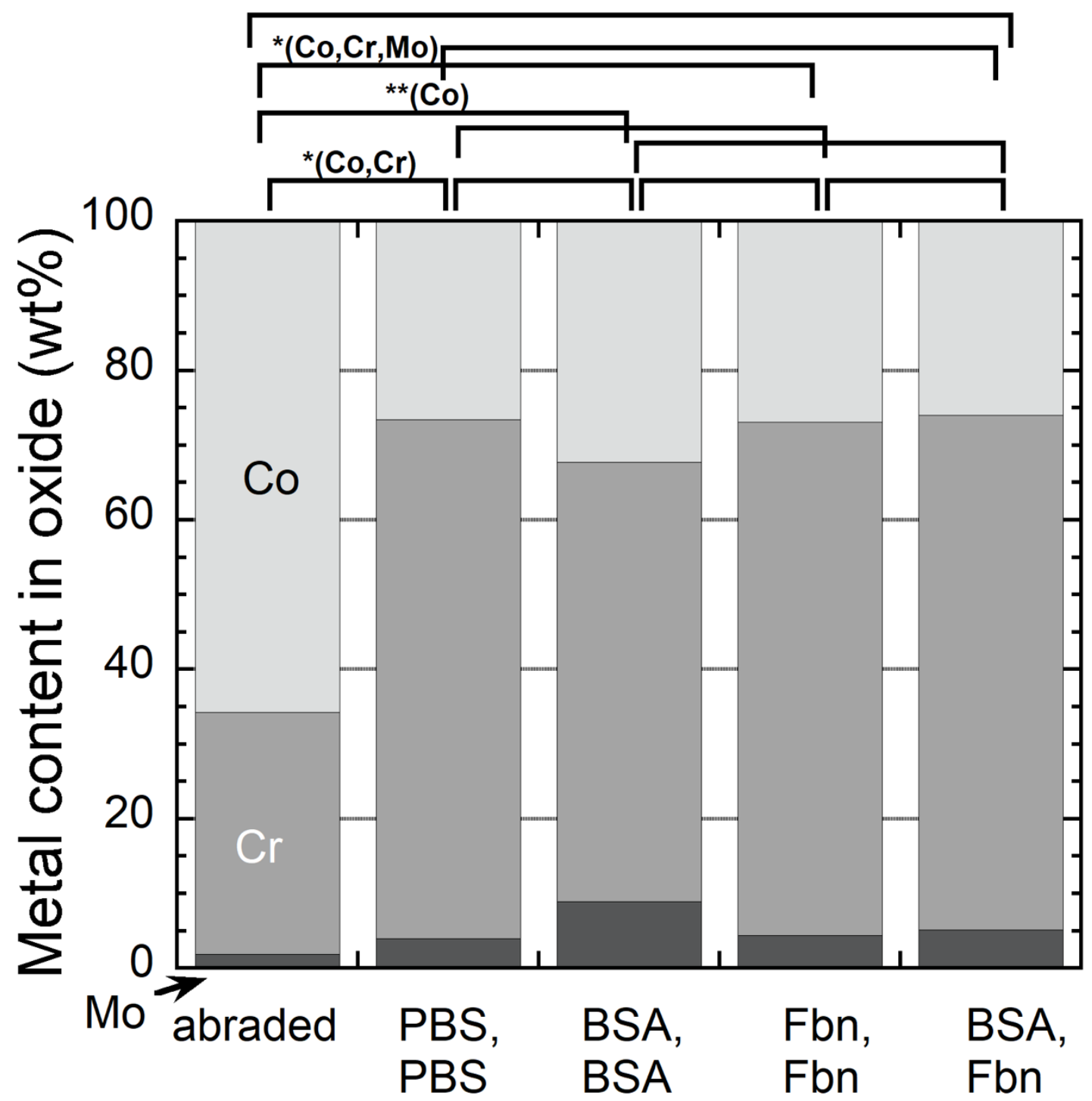

Figure 6. Relative metal content in the outermost surface oxide of the CoCrMo alloy being abraded (as non-exposed reference) and exposed to four sequential solutions ( $\mathrm{pH}$ 7.2-7.4); PBS followed by PBS (PBS, PBS), PBS+ $40 \mathrm{~g} / \mathrm{L}$ BSA followed by PBS +40 g/L BSA (BSA, BSA), PBS+2.67 g/L Fbn followed by PBS+2.67 g/L Fbn (Fbn, Fbn), and PBS+ $40 \mathrm{~g} / \mathrm{L} \mathrm{BSA}$ followed by $2.67 \mathrm{~g} / \mathrm{L}$ Fbn (BSA, Fbn); exposed at $37{ }^{\circ} \mathrm{C}$ for 24 $\mathrm{h}$; studies by means of X-ray photoelectron spectroscopy; statistically significant differences are indicated by asterisks: $* \mathrm{p}<0.05, * * \mathrm{p}<0.01 ; \mathrm{n}=2$. 
Table 4. Observed binding energies and assignments of Co, Cr, Mo, N, C and O of the outermost surface of CoCrMo disks based on X-ray photoelectron spectroscopy (XPS) measurements $[44,45]$.

\begin{tabular}{|c|c|c|}
\hline Sample & Binding energy $^{\mathrm{a}}(\mathrm{eV})$ & Assignment \\
\hline \multirow[t]{2}{*}{$\operatorname{Co~} 2 \mathrm{p}_{3 / 2}$} & $778.8 \pm 0.16$ & Co metal \\
\hline & $782.3 \pm 2.3$ & Oxidized Co \\
\hline \multirow[t]{2}{*}{$\mathrm{Cr} 2 \mathrm{p}_{3 / 2}$} & $574.6 \pm 0.16$ & Cr metal \\
\hline & $577.7 \pm 0.8$ & $\mathrm{Cr}(\mathrm{III})$ \\
\hline \multirow[t]{2}{*}{ Mo 3d } & $228.2 \pm 0.2,231.3 \pm 0.2$ & Mo metal \\
\hline & $232.6 \pm 0.3,235.8 \pm 0.1$ & $\mathrm{MoO}_{3}$ \\
\hline \multirow[t]{2}{*}{$\mathrm{N} 1 \mathrm{~s}$} & $\begin{array}{l}394.4 \pm 0.07 \text { (only detected if } \\
\text { no BSA present) }\end{array}$ & Metal nitride \\
\hline & $399.5 \pm 0.9$ & Amine/amide species \\
\hline \multirow[t]{3}{*}{$\mathrm{C} 1 \mathrm{~s}$} & 285.0 & C-C, C-H bonds \\
\hline & $286.7 \pm 0.2$ & C-N, C-O bonds \\
\hline & $288.5 \pm 0.3$ & $\mathrm{C}=\mathrm{C}-\mathrm{O}, \mathrm{O}=\mathrm{C}-\mathrm{N}$ bonds \\
\hline \multirow[t]{3}{*}{$\mathrm{O} 1 \mathrm{~s}$} & $530.7 \pm 0.3$ & Lattice oxide \\
\hline & $531.8 \pm 0.3$ & $\begin{array}{l}\text { Hydroxide, hydrated, or } \\
\text { defective oxide }\end{array}$ \\
\hline & $533.2 \pm 0.3$ & Water, organic oxide \\
\hline
\end{tabular}

${ }^{a}$ all binding energies normalized to $C 1 \mathrm{~s}$ at $285.0 \mathrm{eV}$

The surface (hydr)oxide was composed of oxidized cobalt (Co $2 \mathrm{p}_{3 / 2}$ at $782.3 \pm 2.3 \mathrm{eV}$ ), $\mathrm{Cr}\left(\mathrm{Cr} 2 \mathrm{p}_{3 / 2}\right.$ at $577.7 \pm 0.8 \mathrm{eV}$ corresponding to $\mathrm{Cr}^{\mathrm{III}}$ ) and $\mathrm{Mo}$ (Mo $3 \mathrm{~d}$ at $232.6 \pm 0.3$ and $235.8 \pm 0.1 \mathrm{eV}$ corresponding to $\mathrm{MoO}_{3}$ ). All exposed CoCrMo surfaces showed an enrichment of $\mathrm{Cr}$, a reduced amount of $\mathrm{Co}$, and an increased amount of Mo in the surface (hydr)oxide. Compared with the non-exposed CoCrMo reference, there was an enrichment of $\mathrm{Cr}(\mathrm{p}<0.05)$ in the surface (hydr)oxide exposed to "PBS, PBS". It is in agreement with previous findings [33, 34] that the (hydr)oxide film is mainly composed of $\mathrm{Cr}_{2} \mathrm{O}_{3}$ and that $\mathrm{Mo}$ and $\mathrm{Co}$ oxides contribute less. There was no significant difference among the specimens exposed in the four different sequential solutions. Note that phosphorus wasn't investigated in this study, but is likely to be incorporated as phosphate in the surface (hydr)oxide after exposure to PBS [35].

\subsection{Sequential release of metals under sliding conditions}

Fig. 7 shows released and non-precipitated amounts of Co (Fig. 7a), Cr (Fig. 7b) and Mo (Fig. 7c) under sliding conditions compared with control samples, for which the released metals derive from the specimen holders and not the specimens. Fig. 7 further compares sliding conditions with static conditions ("non-slide") after $24 \mathrm{~h}$. 

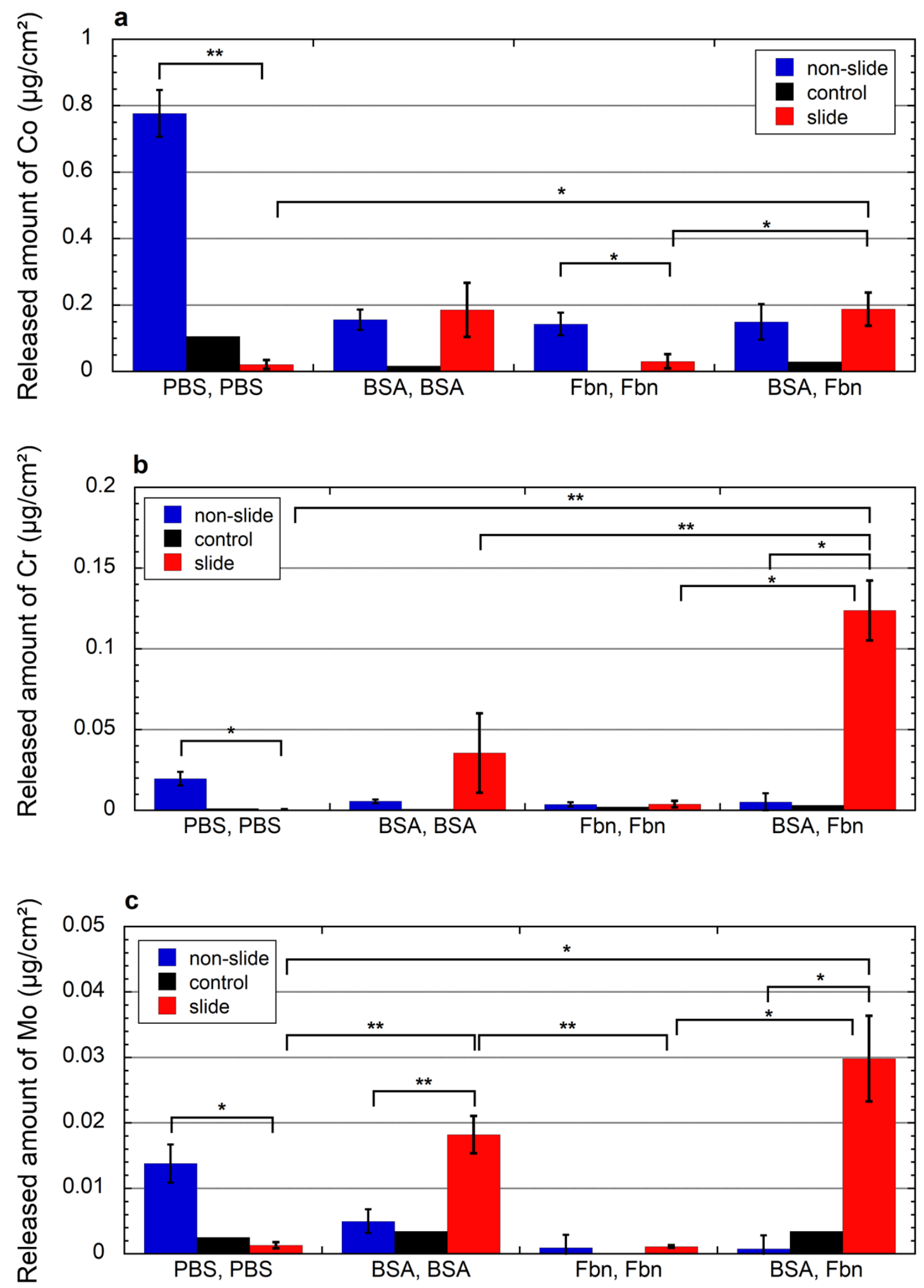

Figure 7. Released and non-precipitated amounts of Co (a), $\mathrm{Cr}$ (b) and Mo (b) in solution from disks of CoCrMo alloy exposed to four solutions under sliding (slide) and non-sliding (non-slide) conditions ( $\mathrm{pH}$ 7.2-7.4); PBS followed by PBS (PBS, PBS), PBS+40 g/L BSA followed by PBS $+40 \mathrm{~g} / \mathrm{L}$ BSA (BSA, BSA), PBS $+2.67 \mathrm{~g} / \mathrm{L}$ Fbn followed by PBS $+2.67 \mathrm{~g} / \mathrm{L}$ Fbn (Fbn, Fbn), and PBS $+40 \mathrm{~g} / \mathrm{L}$ BSA followed by 2.67 
$\mathrm{g} / \mathrm{L}$ Fbn (BSA, Fbn); exposed at $37^{\circ} \mathrm{C}$ and sampled after $24 \mathrm{~h}$. The control denotes the background control in the test-setup under sliding conditions (Fig. 2). The error bars show the standard deviation of independent triplicate disks. Significant differences are indicated by asterisks: ${ }^{*} \mathrm{p}<0.05,{ }^{* *} \mathrm{p}<0.01 ; \mathrm{n}=3$.

The specimen holders, which were made of stainless steel (confirmed by energy dispersive X-ray spectroscopy), released all three metals to some extent. This points towards contamination from previous runs (involving both CoCrMo materials and phosphate-containing solutions) and an insufficient cleaning procedure. The cleaning procedure was a detergent and organic solvent-based method using ultrasound and several rinsing steps. The cleaning procedure was designed to remove proteins but to keep the surface oxide, possibly including metal contaminants, of stainless steel intact.

The released and non-precipitated amounts of metals in PBS solutions under sliding conditions were significantly lower $(\mathrm{p}<0.05)$ than under static conditions, and even lower than the control sample (with the only contribution deriving from the specimen holder). This phenomenon may be caused by the locally increased surface $\mathrm{pH}$ outside the sliding surfaces, and consequently corrosion product deposition [36]. The reduced release of Co was also statistically significant in the "Fbn, Fbn" sequence under sliding as compared to static conditions, Fig.7a. These phenomena were probably caused by the formation and removal of metal-protein aggregates and wear particles from the contact area, as supported by an earlier found rapid decrease in friction coefficient due to removal of protein aggregates from the contact area in a similar test rig [28]. We speculate that the precipitation processes could have been accelerated under sliding conditions (either due to the increase of $\mathrm{pH}$ outside of the wear track or due to increased protein aggregation, or both). This is supported by the observation that the control included higher amounts of aqueous cobalt as compared to the solution in contact with the CoCrMo specimen under sliding conditions in the "PBS, PBS" solution. In the BSA-containing solutions, the released amount of $\mathrm{Cr}$ was greater than control samples and samples exposed under static conditions, Fig.7b. This agrees with a previous study [37], which showed that tribocorrosion and fretting corrosion could induce the formation of particles, which contain more chromium. Also, these $\mathrm{Cr}$ and phosphateenriched particles were mainly found in the synovial fluid [37]. The released amount of $\mathrm{Cr}$ in the mixed protein containing solutions, as compared to single protein solutions, was statistically significant higher, further discussed in the section 'Vroman effect'. The released amount of Mo in the BSA-containing solutions was higher than in static conditions and for control samples, Fig.7c. This observation is likely explained by an increased metal release in the BSA-containing solutions and reduced binding of molybdate ions to precipitating proteins as compared to $\mathrm{Cr}^{\mathrm{III}}$ and $\mathrm{Co}^{\mathrm{II}}$ ions. It is clear that $\mathrm{Cr}^{\mathrm{III}}$ and $\mathrm{Co}^{\mathrm{II}}$ ions bind strongly (irreversibly) to albumin [6-9], however molybdate ions have also been found to bind to albumin under certain conditions, but only at certain potential values and in a reversible manner $[25,26]$. A previous study 
investigating the release of $\mathrm{Co}, \mathrm{Cr}$, and Mo from CoCrMo in PBS and PBS $+36 \mathrm{~g} / \mathrm{L} \mathrm{BSA}$ at no applied potential in static and sliding conditions, after shorter time periods than investigated in this study, revealed a significant increase for all three metals in both PBS and PBS $+36 \mathrm{~g} / \mathrm{L}$ BSA under sliding as compared to static conditions, and in the presence of BSA as compared to PBS alone [31].

The coefficient of friction during the $24 \mathrm{~h}$ exposures under sliding conditions is shown in Fig. 8.

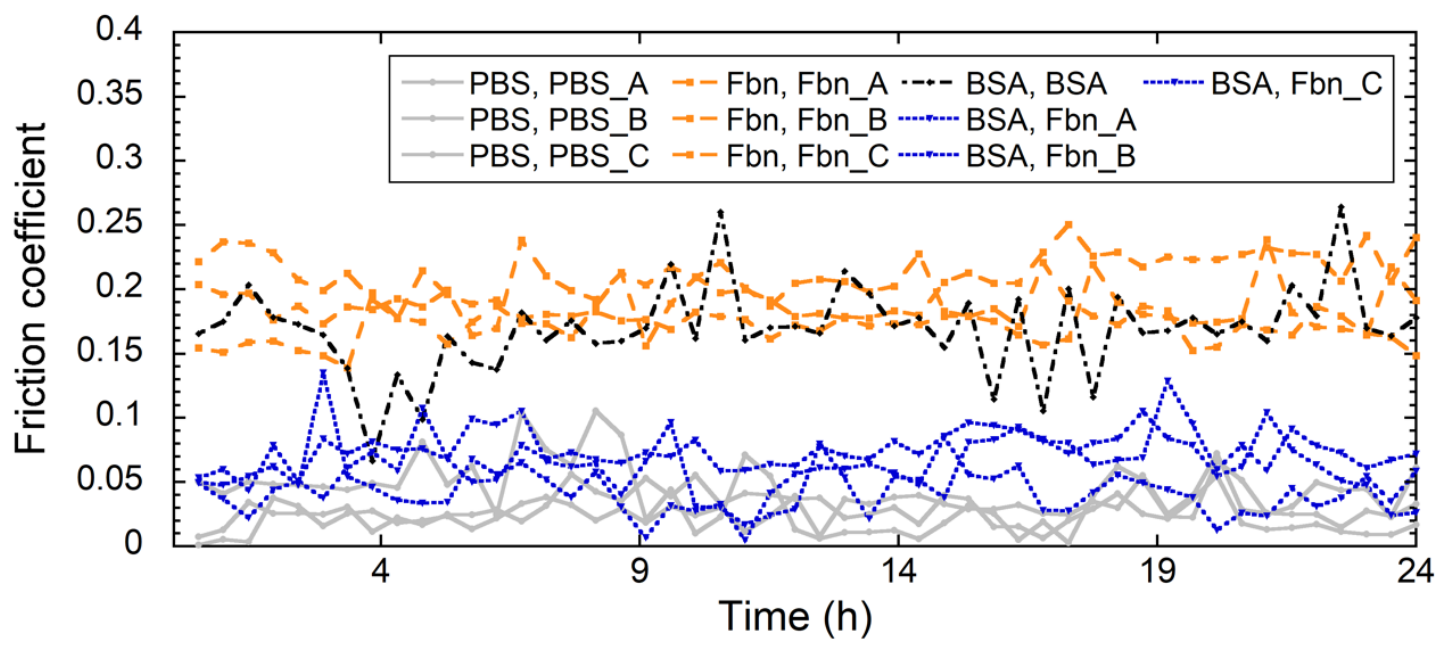

Figure 8. Changes in coefficient of friction under sliding conditions. A, B, C denotes different replicate measurements. Only one data set available for "BSA, BSA".

The coefficient of friction of the "Fbn, Fbn" sequence was clearly larger than for the other sequential exposures. The coefficient of friction of "PBS, PBS" was the smallest among the solutions. According to previous findings [38], the surface roughness is expected to decrease with the adsorption of BSA and Fbn, and the roughness after adsorption of Fbn should be lower than after adsorption of BSA. Similarly, a rougher surface for stainless steel was observed in PBS as compared to a whey protein solution in a previous study under sliding conditions [39]. The surface roughness is not expected to be the most important factor for the true contact area, but the softness of the surface is important, as the hardness of the softer surface is indirectly proportional to the true surface area [40]. It is expected that the protein layers might be softer than the UHMWPE counter surface and that Fbn forms a thicker layer as compared to BSA (c.f. Fig. 5), which hence increases the contact area and the coefficient of friction. The effect of BSA remains unclear from the friction measurements, since only one data set of the friction coefficient was available for the sequence "BSA, BSA". The sequence "BSA, Fbn" was resulting in significantly lower coefficients of friction as compared to "Fbn, Fbn" and it is unclear whether this is caused by a thinner adsorbed layer in the mixed 
solution [[24]] or another reason. Previous studies also highlighted the ability of protein layers to entrap wear particles [41, 42], which could increase the overall wear.

\subsection{Influence of metal precipitation}

In order to investigate the effect of metal precipitation for measurements under the sliding conditions, the mass ratios of $\mathrm{Co}, \mathrm{Cr}$, and $\mathrm{Mo}$ between the bottom and top part of collected solution samples after centrifugation was evaluated, Fig. 9. If this ratio is 1 , no precipitation is expected, as the metals would be present as ions or soluble species. In most cases, however, the mass ratios were above one, which means that the metals were enriched in the bottom of the centrifuge tube. This was more pronounced for protein-containing solutions than for PBS alone in the case of $\mathrm{Co}$ and $\mathrm{Cr}$. $\mathrm{Cr}^{\mathrm{III}}$ is expected to bind more efficiently to proteins as compared to $\mathrm{Co}^{\mathrm{II}}$ and molybdate [10, 43], and this is clearly indicated by the mass ratios, Fig. 9. $\mathrm{Cr}$ is initially more preferentially found in the heavier bottom part of the centrifuge tubes as compared to Co - especially for protein-containing solutions, Figs. 9a and 9b. In contrast, Mo is initially found more preferentially in the top part of the centrifuge tubes (ratio is lower than 1), which indicates repulsion from protein aggregates or wear particles, Fig 9c. This could be due to similar charge of molybdate ions, wear particles, and proteins. After longer exposure time, however, Mo is found more preferentially in the bottom part of the centrifuge tubes in the case of the protein-containing solutions. 

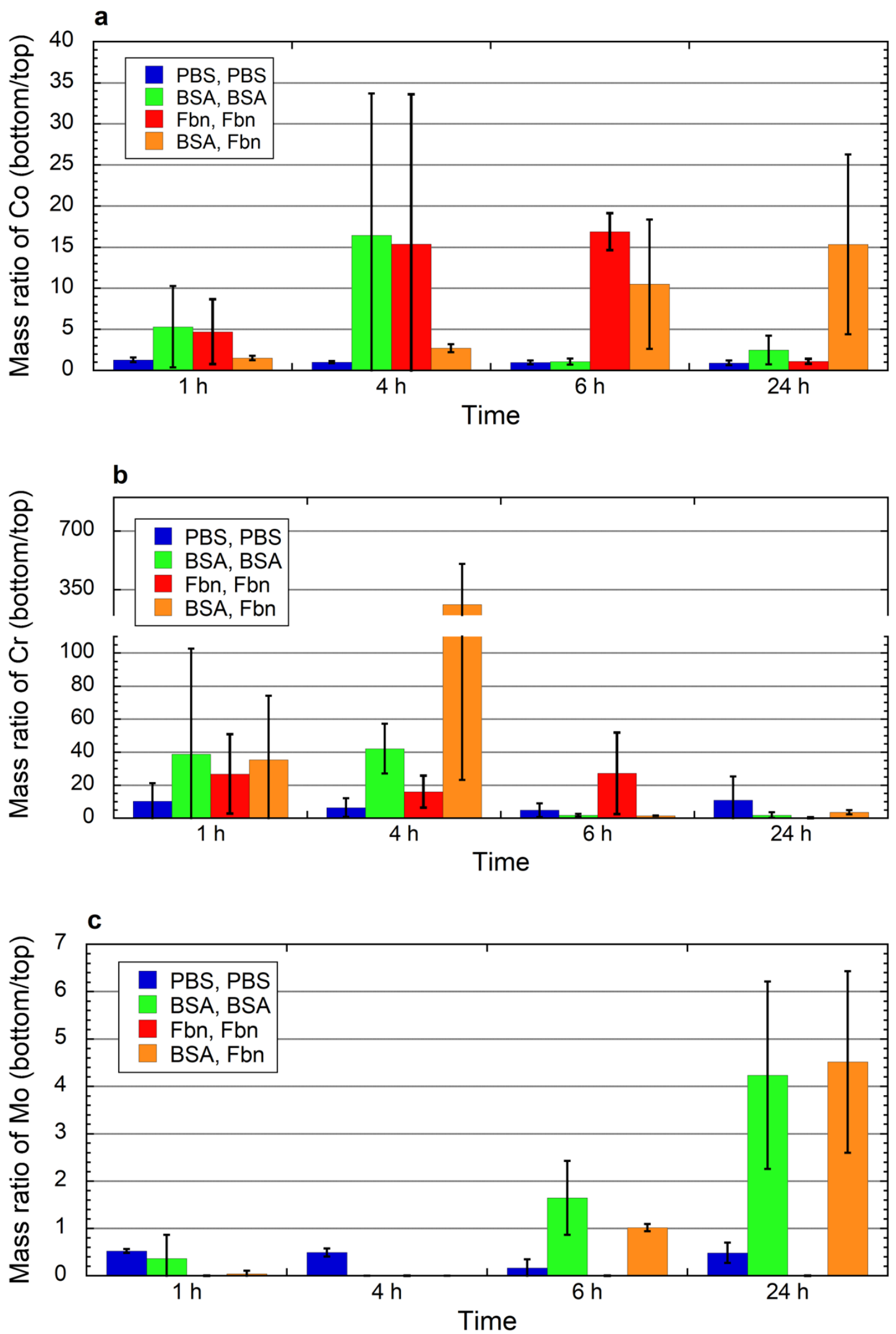

Figure 9. The mass ratios of $\mathrm{Co}(\mathrm{a}), \mathrm{Cr}$ (b) and $\mathrm{Mo}$ (c) between the bottom and top part of collected solution samples (under sliding conditions) after centrifugation. The Mo 
values that are equal to zero mean that the bottom fraction was non-detectable. The bottom part of the centrifuge tube contains heavier constituents (wear particles, protein aggregates), if present, compared to the top part of the centrifuge tube.

It was clearly indicated that the experimental conditions induced metal precipitation, which explains why the released amounts of metals were lower under sliding conditions as compared to static conditions and control samples. It can hence be concluded from our experimental data that PBS and protein-containing solutions pose a risk to underestimating the release of especially $\mathrm{Co}$ and $\mathrm{Cr}$ from CoCrMo under sliding and static conditions.

\subsection{Vroman effect}

A previous study on stainless steel $316 \mathrm{~L}$ in a similar test setup in static conditions revealed significantly increased metal release in solutions containing first BSA and then Fbn, as compared to single protein solutions [22]. In this study on CoCrMo, we did not find an increase. Although this effect could have been overshadowed by the strong metal precipitation in this study, we did also not detect any difference in surface oxide composition by means of XPS. However, in sliding conditions, there was an increase of released $\mathrm{Cr}$ in the mixed protein solution as compared to single protein solutions. From this study alone, no conclusion can be drawn on the Vroman effect.

\subsection{Significance, limitations, and future directions}

This work showed the influence of protein aggregation on accurate interpretations of metal release studies. The true released amount of metals can be underestimated due to protein aggregation and precipitation of protein aggregates and solidified metal species, especially when exploring the metal release in protein-containing solutions.

The main limitation of this study was the experimental setup for the tests under sliding condition. There was a significant released amount of metals in the control solution samples, which was caused by contamination from the stainless steel holders. Future studies should focus on combining different surface analytical, electrochemical, and solution analytical methods to investigate and compare physical (wear), electrochemical and other chemical degradation processes simultaneously. Also, protein aggregation and precipitation processes should be quantified and accounted for. 


\section{CONCLUSIONS}

This study aimed at investigating the effect of different proteins (albumin and fibrinogen) on metal release from CoCrMo in static and sliding conditions. The following main conclusions were drawn:

1. PBS and proteins could induce significant precipitation of metals and protein aggregates, which resulted in strong underestimation of released metals, especially under sliding conditions and for released $\mathrm{Co}$ and $\mathrm{Cr}$. This effect was minor for released Mo.

2. The released amounts of metals increased with time under static conditions, except for solutions containing high protein concentrations (due to increased precipitation).

3. Cr was strongly enriched in the surface oxide of CoCrMo in all solutions, and this was accompanied by metal release dominated by Co.

4. Protein aggregates were found to precipitate on the surface of CoCrMo under static conditions.

5. Compared with static conditions, the amount of measurable (non-precipitated) released metals under sliding conditions was lower in PBS and Fbn, but higher in BSA-containing solutions.

6. The friction coefficient was clearly greater in the solution containing only fibrinogen as compared to PBS. 


\section{References}

1. Ren F, Zhu W, and Chu K (2016) Fabrication, tribological and corrosion behaviors of ultra-fine grained Co-28Cr-6Mo alloy for biomedical applications. J Mech Behav Biomed Mater 60: 139-147.

2. Gilbert J (2017) Corrosion in the human body: Metallic implants in the complex body environment. Corrosion 73: 1478-1495.

3. Stemp DLSMM (2001) Electrochemical methods in tribocorrosion: a critical appraisal. Electrochimica Acta 46: 3913-3929.

4. Hedberg YS (2018) Role of proteins in the degradation of relatively inert alloys in the human body. npj Materials Degradation 2: 26.

5. Shenoy AA, Kurtz SM, and Gilbert JL (2021) Nontribological corrosion modes dominate wrought CoCrMo acetabular taper corrosion: A retrieval study. Journal of Biomedical Materials Research Part B: Applied Biomaterials.

6. Yang J and Black J (1994) Competitive binding of chromium, cobalt and nickel to serum proteins. Biomaterials 15: 262-268.

7. Friedberg F (1974) Effects of Metal Binding on Protein Structure. Quarterly Reviews of Biophysics 7: 1-33.

8. Paustenbach DJ, Tvermoes BE, Unice KM, Finley BL, and Kerger BD (2013) A review of the health hazards posed by cobalt. Critical Reviews in Toxicology 43: 316-362.

9. Bal W, Sokołowska M, Kurowska E, and Faller P (2013) Binding of transition metal ions to albumin: sites, affinities and rates. Biochimica et Biophysica Acta (BBA)-General Subjects 1830: 5444-5455.

10. Hedberg YS, Dobryden I, Chaudhary H, Wei Z, Claesson P, and Lendel C (2019) Synergistic effects of metal-induced aggregation of human serum albumin. Colloids and Surfaces B: Biointerfaces 173: 751-758.

11. Österberg R, Sjöberg B, and Persson D (1981) Cr (III)-Induced polymerization of human albumin. Biological Trace Element Research 3: 157-167.

12. Sargeant A and Goswami T (2007) Hip implants - Paper VI - Ion concentrations. Materials \& Design 28: 155-171.

13. Münch HJ, Jacobsen SS, Olesen JT, Menné T, Søballe K, Johansen JD, and Thyssen JP (2015) The association between metal allergy, total knee 
arthroplasty, and revision. Acta orthopaedica 86: 378-383.

14. Noli F, Papadopoulos P, Kolias P, Tsiridis E, Papavasiliou K, and Sayegh F (2019) Neutron activation analysis for determination of metal ions in biological fluids of patients after CoCrMo arthroplasty. Journal of Radioanalytical and Nuclear Chemistry 322: 621-628.

15. Roos PM, Vesterberg O, and Nordberg M (2006) Metals in motor neuron diseases. Experimental Biology and Medicine 231: 1481-1487.

16. Roos PM, Vesterberg O, Syversen T, Flaten TP, and Nordberg M (2013) Metal concentrations in cerebrospinal fluid and blood plasma from patients with amyotrophic lateral sclerosis. Biological Trace Element Research 151: 159-170.

17. Cortizo MC, de Mele MFL, and Cortizo AM (2004) Metallic dental material biocompatibility in osteoblastlike cells. Biological Trace Element Research 100: 151-168.

18. Koronfel MA, Goode AE, Weker JN, Tay SE, Stitt CA, Simoes TA, Mosselmans JFW, Quinn P, Brydson R, and Hart A (2018) Understanding the reactivity of CoCrMo-implant wear particles. npj Materials Degradation 2: 8 .

19. Hedberg Y, Karlsson M-E, Blomberg E, Odnevall Wallinder I, and Hedberg J (2014) Correlation between surface physicochemical properties and the release of iron from stainless steel AISI 304 in biological media. Colloids and Surfaces B: Biointerfaces 122: 216-222.

20. Hirsh SL, McKenzie DR, Nosworthy NJ, Denman JA, Sezerman OU, and Bilek MMM (2013) The Vroman effect: Competitive protein exchange with dynamic multilayer protein aggregates. Colloids and Surfaces B: Biointerfaces 103: 395404.

21. Schricker SR, Palacio M, and Bhushan B, Modulating Protein Adhesion and Conformation with Block Copolymer Surfaces, in Handbook of Nanomaterials Properties. 2014, Springer. p. 1343-1376.

22. Hedberg Y, Karlsson M-E, Wei Z, Žnidaršič M, Odnevall Wallinder I, and Hedberg J (2017) Interaction of albumin and fibrinogen with stainless steel influence of sequential exposure and protein aggregation on metal release and corrosion resistance. Corrosion 73: 1423-1436.

23. Myant CW and Cann P (2014) The effect of transient conditions on synovial fluid protein aggregation lubrication. Journal of the Mechanical Behavior of Biomedical Materials 34: 349-357. 
24. Parkes M, Myant C, Cann PM, and Wong JSS (2015) Synovial Fluid Lubrication: The Effect of Protein Interactions on Adsorbed and Lubricating Films. Biotribology 1-2: 51-60.

25. Martin EJ, Pourzal R, Mathew MT, and Shull KR (2013) Dominant role of molybdenum in the electrochemical deposition of biological macromolecules on metallic surfaces. Langmuir 29: 4813-22.

26. Martin EJ, Mathew MT, and Shull KR (2015) Viscoelastic properties of electrochemically deposited protein/metal complexes. Langmuir 31: 4008-17.

27. Fialho JC, Fernandes PR, Eça L, and Folgado J (2007) Computational hip joint simulator for wear and heat generation. Journal of Biomechanics 40: 2358-2366.

28. Hedberg YS, Pettersson M, Pradhan S, Odnevall Wallinder I, Rutland MW, and Persson C (2015) Can cobalt(II) and chromium(III) ions released from joint prostheses influence the friction coefficient? ACS Biomaterials Science \& Engineering 1: 617-620.

29. Hedberg Y and Odnevall Wallinder I (2014) Metal release and speciation of released chromium from a biomedical CoCrMo alloy into simulated physiologically relevant solutions. Journal of Biomedical Materials Research Part B: Applied Biomaterials 102: 693-699.

30. Yan Y, Yang H, Su Y, and Qiao L (2016) Study of the tribocorrosion behaviors of albumin on a cobalt-based alloy using scanning Kelvin probe force microscopy and atomic force microscopy. Electrochemistry Communications 64: 61-64.

31. Espallargas N, Torres C, and Muñoz AI (2015) A metal ion release study of CoCrMo exposed to corrosion and tribocorrosion conditions in simulated body fluids. Wear 332: 669-678.

32. Clark GCF and Williams DF (1982) The effects of proteins on metallic corrosion. Journal of Biomedical Materials Research 16: 125-134.

33. Wei Z, Edin J, Karlsson AE, Petrovic K, Soroka IL, Odnevall Wallinder I, and Hedberg Y (2018) Can gamma irradiation during radiotherapy influence the metal release process for biomedical CoCrMo and 316L alloys? Journal of Biomedical Materials Part B 106: 2673-2680.

34. Contu F, Elsener B, and Böhni H (2003) Electrochemical Behavior of CoCrMo Alloy in the Active State in Acidic and Alkaline Buffered Solutions. Journal of The Electrochemical Society 150. 
35. Lewis AC, Kilburn M, Heard P, Scott T, Hallam K, Allen G, and Learmonth I (2006) The entrapment of corrosion products from CoCr implant alloys in the deposits of calcium phosphate: a comparison of serum, synovial fluid, albumin, EDTA, and water. Journal of orthopaedic research 24: 1587-1596.

36. Gilbert JL, Buckley CA, and Jacobs JJ (1993) In vivo corrosion of modular hip prosthesis components in mixed and similar metal combinations. The effect of crevice, stress, motion, and alloy coupling. Journal of biomedical materials research 27: 1533-1544.

37. Wang Q, Eltit F, Garbuz D, Duncan C, Masri B, Greidanus N, and Wang R (2020) CoCrMo metal release in metal-on-highly crosslinked polyethylene hip implants. Journal of Biomedical Materials Research Part B: Applied Biomaterials 108: 1213-1228.

38. Silva-Bermudez P, Ramirez G, and Rodil SE, Corrosion resistant coatings for dental implants, in Bio-Tribocorrosion in Biomaterials and Medical Implants. 2013. p. 250-308.

39. Atapour M, Wei Z, Chaudhary H, Lendel C, Odnevall Wallinder I, and Hedberg Y (2019) Metal release from stainless steel 316L in whey protein - and simulated milk solutions under static and stirring conditions. Food Control 101: 163-172.

40. Popov VL, Contact mechanics and friction: Physical Principles and Applications. 2010, NY: Springer.

41. Sun D, Wharton JA, and Wood RJK, The Effects of Protein and pH on the TriboCorrosion Performance of Cast CoCrMo - A Combined Electrochemical and Tribological Study, in Advanced Tribology, J. Luo, et al., Editors. 2010, Springer Berlin Heidelberg. p. 825-826.

42. Arenas M, Conde A, De Frutos A, and de Damborenea J (2014) Electrochemical noise measurements of AISI 316L during wear in simulated physiological media. Corrosion Engineering, Science and Technology 49: 656-660.

43. Tainer JA, Roberts VA, and Getzoff ED (1991) Metal-binding sites in proteins. Current Opinion in Biotechnology 2: 582-591.

44. Biesinger MC, Payne BP, Grosvenor AP, Lau LWM, Gerson AR, and Smart RSC (2011) Resolving surface chemical states in XPS analysis of first row transition metals, oxides and hydroxides: $\mathrm{Cr}, \mathrm{Mn}, \mathrm{Fe}, \mathrm{Co}$ and Ni. Applied Surface Science 257: 2717-2730.

45. Alexander V. Naumkin AK-V, Stephen W. Gaarenstroom, and Cedric J. Powell, NIST X-ray Photoelectron Spectroscopy Database. 2012. 